\title{
Testimonio y práctica artística en el Campo de Prisioneros de Chacabuco 1973-1974. El teatro de Mario Molina
}

\section{Testimony and Artistic Practice in the Chacabuco Prison Camp 1973-1974. Mario Molina's Theater}

\author{
Francisca Durán M. \\ Universidad Academia de Humanismo Cristiano \\ Francisca.duran@uacademia.cl
}

\section{Resumen}

El presente artículo aborda la experiencia de la sobrevivencia de los presos políticos en el Campo de Prisioneros de Chacabuco durante la dictadura cívico-militar chilena, a través de la práctica artística teatral, entre 1973 y 1974. A modo de hipótesis se plantea que el teatro permitió a los presos mermar el drama y construir transitoriamente realidades diferentes, suspendiendo la realidad impuesta y creando otras alternativas. La pregunta principal es de qué manera el corpus dramático de Mario Molina, escrito durante su detención, generó estrategias de supervivencia y condiciones para interpretar los nuevos hechos extraordinarios que estaban sucediendo. El teatro de Mario Molina en cuanto a escritura, puesta en escena y recepción se analiza desde su propia dramaturgia, así como desde el campo testimonial.

Palabras clave: Testimonio, práctica artística, teatro, prisión política en Chile, Chacabuco.

\section{Abstract}

The following article approaches the use of theatre as a survivance strategy in the experience of political prisoners in Chacabuco, a prison camp established during the Chilean dictatorship between 1973 and 1974 in the north of the country. Our hypothesis is that theatre allowed the prisoners to experience alternative existences to their misfortune, new realities that could temporarily suspend their dramatic circumstances. Our specific question is about the dramatic production of the prisoner Mario Molina, and the way it propelled survival strategies and tools to interpret the new life circumstances at the prison camp. Mario Molina's theatre proposal will be analyzed in itself, as dramatic writing, staging and performance, as well as testimony.

Keywords: Testimony, theater, artistic practice, political prison in Chile, Chacabuco. 


\section{Introducción}

El propósito de este artículo es abordar la experiencia de la supervivencia de los presos políticos en el Campo de Prisioneros de Chacabuco, ${ }^{1}$ a través de la práctica artística teatral, durante la primera ola represiva de la dictadura cívico-militar chilena, entre 1973 y 1974. Es decir, a modo de hipótesis se plantea que el teatro permitió a los presos, en ocasiones, mermar el drama y construir transitoriamente realidades diferentes, suspendiendo la realidad impuesta y creando otras alternativas. Estas otras realidades se inscriben en el marco de la experiencia cultural y política de los presos que antecede a su detención, así como en el gesto refundacional; entendiendo por ello, cuando los presos comenzaron a re-habitar la antigua oficina salitrera.

En términos específicos, la pregunta que sostiene a esta hipótesis es de qué manera el corpus dramático de Mario Molina Domínguez, escrito durante su detención en el Campo de Prisioneros, ${ }^{2}$ generó estrategias de supervivencia y condiciones para interpretar los nuevos hechos extraordinarios que estaban sucediendo. El libro Teatro en Chacabuco (Campo de Concentración), publicado por el autor en el año 2008, reúne las obras teatrales de la prisión política. ${ }^{3}$ Asimismo, la publicación también incluye parte de su posterior producción artística e intelectual en los capítulos "Teatro post Chacabuco", "Relatos y notas" y "Documentos", escritos en su mayoría entre los años 2003 y 2005.

En este artículo nos centraremos en el primer capítulo, "Teatro en Chacabuco", puesto que mediante estas dramaturgias de pequeño formato o gags $^{4}$ tenemos acceso

1 En este artículo seguiremos el nombre "Campo de Prisioneros de Chacabuco" utilizado por la Corporación Memoria Chacabuco y diversos escritos oficiales, jurídicos, académicos y políticos. No obstante, huelga señalar que, en innumerables referencias brindadas por los testimoniantes, la nomenclatura usada es la de "Campo de Concentración”, clara analogía con el imaginario del Holocausto (Montealegre, Memorias Eclipsadas). La oficina salitrera Chacabuco se encuentra en el desierto de Atacama a $102 \mathrm{~km}$ de Antofagasta y una parte de ella fue utilizada como centro de prisioneros durante la dictadura cívico-militar en noviembre de 1973 hasta abril de 1975. No obstante, "desde mediados de 1974 el campo empezó a desocuparse gradualmente, en la medida en que los presos políticos fueron dejados en libertad o trasladados a otros lugares en Santiago y Valparaíso: Tres Álamos, Ritoque, Puchuncaví y Melinka" (Informe de la Comisión Nacional sobre Prisión Política y Tortura 279).

2 El autor nació en Valparaíso en 1925. Estudió y se tituló de Ingeniero Mecánico en la Universidad Federico Santa María. Ingresó al Partido Socialista en 1968. Fue detenido en el Estadio Nacional en septiembre de 1973 y luego fue trasladado a Chacabuco en noviembre de dicho año hasta julio de 1974. Murió el 27 de mayo de 2016 en su ciudad natal.

3 En la primera parte del libro se reúnen ocho textos dramáticos, cuyos nombres son: ¿Quién está cuerdo?; Una sorpresa fatal; La incomunicación; Primero incomunicación, luego...; Como se evitó la tercera guerra mundial; El señor gerente general; El servicio militar; y El asesinato del tío Valentín. Nuestro autor, durante su detención en Chacabuco, escribió estas piezas en un cuaderno personal que conservó posteriormente. A partir de esta experiencia original, Mario Molina fue reescribiendo las obras para su publicación de 2008. En la mayoría de estas aparece al inicio que fueron corregidas y actualizadas. En el primer gag del libro advierte que se han efectuado algunos cambios para actualizar el mismo tema, cambiando además el nombre Locos por ¿Quién está cuerdo? También, agrega que la obra titulada Una sorpresa fatal originalmente llevaba por nombre Pendiente, la cual no se alcanzó a montar en Chacabuco. Sobre esta misma, señala que ha sido corregida y actualizada, además de agregar el clímax que faltaba. El único croquis con la escenografía y el reparto que disponemos es de ¿Quién está cuerdo?, publicado en el libro.

4 El autor llama gag u "obra chica" a sus textos dramáticos, cuya característica es la extensión breve en número de 
a un tipo de práctica artística referida a la experiencia de la prisión política: el teatro en cuanto escritura. En tanto, las referencias a la puesta en escena de las obras y su recepción provienen de otras fuentes testimoniales, como el testimonio del propio Mario Molina y de otros expresos políticos que fueron testigos de su teatro. ${ }^{5}$

Desde esta impronta, lo testimonial se comprende en un doble juego: primero, en el reconocimiento de la obra dramática -y del arte en general- como forma de conocimiento y, segundo, en el "acto de autor", como sostiene Ileana Diéguez, "en el que se tejen o montan experiencias propias con las de otros, acotado por el doble régimen de transmitir e inquietar, pese a todo, el fondo de incomunicabilidad de los acontecimientos" (89). En este sentido, la obra de nuestro autor se inscribe en una experiencia comunitaria que escenifica los imaginarios y deseos colectivos en los nuevos escenarios de Chacabuco. Por tanto, la reconstrucción testimonial de escenas y escenarios habilita la emergencia autoral para la creación teatral.

El acto de autor de Mario Molina se aproxima a la dimensión de la persona testimoniante cuando publica voluntariamente sus obras más de treinta años después de su experiencia en la prisión. Asimismo, se torna significativo el nombre que el propio creador brinda a su práctica, autodenominándose "Escribidor". Este nombre aparece en la misma escena chacabucana y pervive en el futuro, añadiendo posteriormente en sus escritos la siguiente firma: "Escribidor: Mario Molina D. Egresado de Chacabuco. Campo de Concentración”. En efecto, observamos que el sujeto testimonial es un sujeto que emerge, que se va construyendo a sí mismo y da sentido a sus propias acciones en diversas temporalidades.

Pues bien, podemos afirmar que las prácticas artísticas son productoras de otras realidades, que transforman y suspenden transitoriamente la realidad impuesta. Por tanto, entenderemos las prácticas como actos performáticos, es decir, en la relación con el hacer o con la puesta en acto, en la cual la palabra performance da cuenta de una implicación política y social "que evoca tanto la prohibición como el potencial para la transgresión” (Taylor 41). De este modo, toda acción performática implica develar las normatividades que están en la base de la construcción de los sistemas que coartan a los individuos y los condicionan en su experiencia cotidiana.

palabras y páginas que contienen los libretos, variando en la publicación de 2008 entre tres y ocho páginas cada uno, exceptuando la obra El asesinato del tío Valentín-ficción en tres actos basada en el esqueleto central de la novela de Agatha Christie El Misterio de Hunter's Lodge-, que posee trece carillas. Exploraremos más adelante algunas razones de por qué compuso varias de sus obras en formato gag.

5 Los seis testimonios orales utilizados en este artículo fueron el resultado de la investigación para la realización del documental La Resistencia de los Metales (Chile, 2017). Esta obra audiovisual fue la culminación del proyecto Fondart Regional Línea de Conservación y Difusión del Patrimonio Inmaterial: "Prácticas culturales como forma de resistencia en el centro de detención Chacabuco, 1973-1974" (2015). Estos testimonios fueron gestados a través del formato de entrevista semiestructurada. En términos metodológicos de la historia oral, nos referimos a la cocreación del testimonio mediante un intercambio dialógico entre la autora del presente artículo y cada uno de los entrevistados. Como señala el historiador oral Alessandro Portelli, "cuando hacemos una entrevista, nos encontramos en presencia de un evento -insisto que es un evento, porque lo creamos nosotros" (38). Para el uso público de estas, los entrevistados autorizaron su contenido a través de la firma de un consentimiento informado que declara poder hacer mención de sus identidades para los requerimientos del guion y fines académicos. 
En tanto, la noción de cotidianidad no es reductible a la rutina diaria, puesto que lo cotidiano puede también contener resistencias tanto al control impuesto desde arriba como a la conformidad internalizada desde abajo. Así, "sería un error asumir a priori que lo cotidiano no es más que un enclave de normalidad despolitizada ignorante de las presiones ejercidas desde arriba para colonizarla" (Jay 52). Dicho esto, es posible apreciar la complejidad política del fenómeno mismo, lo cual implica comprender la cotidianidad como un campo abierto a las exploraciones antidisciplinarias, permitiendo, en este caso, que una comunidad de individuos desde su creatividad ejerza una práctica descolonizadora que subvierte a la ideología opresora.

De acuerdo con lo señalado, las prácticas artísticas son registros que quedan de esa normalidad construida en una excepcionalidad, como formas de interpretar los nuevos hechos extraordinarios que sucedieron en la prisión política o, dicho en otras palabras, como formas de restaurar material y simbólicamente una comunidad fracturada. Desde este lugar, la práctica artística será entendida no solo en su artisticidad, sino como un modo de operación, un quehacer -individual y colectivo- y un proceso comunicativo en circunstancias límites o en contextos de "dramas sociales", como propone Diéguez al referirse a situaciones extraordinarias de la vida social en general, dominados por un estado de violencia que ha producido la rotura del tejido social y simbólico (79). En efecto, las categorías estéticas -la obra de arte, el o la artista y la circulación- cumplen otra función en un campo de personas presas políticas, puesto que las prácticas germinan en un ámbito de excepcionalidad y en un tiempo suspendido que altera radicalmente la cotidianidad.

\section{¿Qué vestigios o restos deja la práctica artística? ¿Qué testimonia?}

Mario Molina, en el prólogo de Teatro en Chacabuco, declara el acento evasivo de sus obras. El teatro desarrollado en Chacabuco "se orientó a olvidar la realidad que vivíamos los prisioneros en ese Campo de Concentración en el que alguno de nosotros podía ser torturado y asesinado en cualquier momento" (13). Este tenor también fue recogido en el prólogo realizado por Jorge Montealegre, quien además interpreta esta intención evasiva de sus obras como una feliz paradoja, pues "el instrumento del olvido -las obras de teatro- resulta ser el registro más perdurable de la experiencia. Es testimonio y patrimonio. Memoria, legado. Para recordar lo que, en su momento, la sobrevivencia recomendaba olvidar" (10). No obstante, para analizar la dramaturgia de Mario Molina más allá de un teatro meramente evasivo, la perspectiva de Diéguez nos brinda un registro diferente al "pensar ciertas prácticas desde el resto que expone la propia materialidad de la obra deviniendo documento, pero también como arte residual de la incompletud testimonial, sin la más mínima vocación restitutiva" (86-87). 
Bajo este prisma, el teatro de Mario Molina no solo expone la propia materialidad de la obra deviniendo documento, en cuanto relatos de huellas de los acontecimientos, sino que también remite a una forma de representación sin clausuras y que está abierta siempre a la interpretación, dado la incompletud testimonial, sobreviviendo "como resto o como fantasma de lo que tuvo allí lugar" (90).

El argumento de Diéguez es significativo para problematizar el carácter evasivo de sus obras. Como se mencionó anteriormente, corresponde al sentido que el propio autor confiere a sus obras en décadas posteriores y cuyo énfasis es compartido por Jorge Montealegre en su lugar de testigo. Desde aquí entendemos que el carácter testimonial tiene un horizonte temporal distinto al momento de la emergencia y práctica artística en la prisión política. Ciertamente las interpretaciones de Mario Molina y Jorge Montealegre -en tanto olvido de la experiencia para el primero, y en tanto documento de la experiencia del olvido para el segundo-colaboran en las posibilidades de ampliar los sentidos en una temporalidad diferente. Como sostiene Stuart Hall, "el sentido no está en el objeto, persona o cosa, ni está en la palabra [...]. El sentido es construido por el sistema de representación. Es construido y fijado por un código, que establece una correlación entre nuestro sistema conceptual y nuestro sistema de lenguaje" (21). El sentido, entonces, es el resultado de una práctica significante: "una práctica que produce sentido, que hace que las cosas signifiquen" (24).

Pues bien, en función de lo señalado, afirmamos que la presencia de las prácticas artísticas es factible encontrarla en las huellas de lo testimonial, debido a que el testimonio refiere a ellas, las interpreta y les da un lugar en la experiencia. No obstante, su experiencia contenida aparece, asimismo, en su propia materialidad: un texto dramático, una poesía, un dibujo. Estos objetos o producciones introducen una nueva experiencia poética, pues tienen otras trayectorias y direcciones en términos interpretativos e incluso contienen capas y texturas que las y los propios testimoniantes desconocen o solo conocen en fragmentos. De este modo, podemos decir que el arte pareciera que liberara aquello inefable e individual que no puede ser referido en términos meramente comunicativos o narrativos.

Dicho lo anterior, ¿qué vestigios o restos deja la práctica artística? ¿Qué testimonia? Ya aseveramos al inicio de este artículo el reconocimiento de la obra dramática y del arte en general como forma de conocimiento. Desde este lugar, el análisis de textos dramáticos en clave testimonial nos conduce a la relación del arte con lo real. El artículo de Sebastián Mauro explica este itinerario desde su dimensión aristotélica en cuanto a las paradojas de la mímesis en su tensión entre el acto creativo en sí mismo y el referente y, como ello perfila la paradoja de la obra de arte: no puede alejarse de aquello que imita (referencia), "pero tampoco puede perder su carácter de creación, la lógica de su entramado interno que la hace una unidad coherente" (8).

En este sentido, "los sucesos que 'imita' el arte deben ajustarse, entonces, a un doble requisito de verosimilitud y necesidad. Con verosimilitud, Aristóteles afirma la condición de que los sucesos se ajusten a un mundo 'posible', ligando la producción 
poética a lo real, alejándola del engaño y la mentira [...]. Por otra parte, la condición de necesidad implica que los sucesos deben desprenderse de una trama coherente y lógica" (Mauro 2). Bajo esta lectura de la mímesis como re-presentación (re-creación) de las acciones humanas (praxis), el requisito de verosimilitud puede extraerse a cualquier tipo de discurso, lo cual desafía la noción de una verdad en sí misma, habilitando, de esta manera, la posibilidad de sentido.

Si bien la obra de arte se encuentra abierta a variaciones de sentido, Mauro en su lectura de Adorno afirma que "la obra de arte no se abre completamente a la interpretación, sino que guarda siempre un resto enigmático que se resiste" (5). La posibilidad del secreto como la experiencia misma del testimonio comparte con la obra de arte la condición de "quedar siempre abierta" (Derrida 14). El carácter enigmático o "residuo mimético" permite que la obra de arte tenga una multiplicidad de mensajes que nunca la agotan. Este carácter de la obra "no apunta a su lógica interna (construcción), sino a su contenido de verdad, a la cuestión de la objetividad de su sentido (su referencia al mundo) (Mauro 7). No obstante, para que esto suceda "la comprensión de toda obra requiere trascender su interioridad" (7) y recurrir al conocimiento conceptual (filosófico) para completar el círculo interpretativo.

Podemos decir que este planteamiento, en torno a la apertura de la obra y su resto enigmático, colabora en una noción de conocimiento articulada en una profunda experiencia humana. En nuestro caso, la práctica artística teatral tiene una función de representación de la experiencia de la prisión política en Chacabuco. Entonces, ante la pregunta central de este apartado sobre qué vestigios o restos deja la obra de arte, a priori podemos responder que siempre deja una huella referencial, es decir, "al mismo tiempo que toman su contenido de lo factual renuncian a esa realidad para transformarla" (Mauro 6).

De acuerdo con lo mencionado previamente, en relación con la excepcionalidad en la que germinan las prácticas artísticas en un centro de prisión política, el planteamiento de Tzvetan Todorov en Frente al Límite se torna fundamental para comprender aquellas experiencias estéticas e intelectuales en circunstancias extremas como fueron los campos de concentración nazis. La actividad del espíritu, como denomina a la actitud de comunión con la belleza (en relación con el arte o la naturaleza), "designa dos acciones que, en sí mismas, son extrañas a la moral: la búsqueda de la verdad y la búsqueda de lo bello. Esta actividad no está reservada a los profesionales del espíritu, sabios o artistas; es accesible a todos" (99). En alusión a esto, Montealegre en su testimonio grafica explícitamente esta situación en Chacabuco, argumentando que la prisión política había quebrado todas las jerarquías entre ellos: "ya no valía mucho ser jefe de partido, o ser el jefe de la oficina, o ser el jefe de la fábrica. Si había una jerarquía anterior entre nosotros, ya no existía. Nos igualaba la desgracia”.

Todorov encuentra en las huellas de los testimonios momentos de contemplación de la naturaleza, encuentros con la lectura, conversaciones y esfuerzos de memoria cuando no había libros, vale decir, todos aquellos rastros donde se experimentaba 
la "libertad del espíritu" como una virtud cotidiana. "Para un prisionero, el espíritu constituye una isla, pequeña pero segura, en el centro mismo de un mar de miseria y desolación" (101). En este escenario complejo, "los futuros escritores prepararon su obra, a veces de manera plenamente consciente" (102). La función de quien escribe en un campo encuentra lugar al menos en dos niveles: "para vivir en poesía esta vida de aquí y poder cantarla", no solo como un combate político a los campos sino también para dejar una huella del sentido de la experiencia. Y, esta huella, bajo su argumento, nos remite a la posibilidad de belleza en el mundo y a la posibilidad de un proyecto creador, "el de la explicación del mundo a través de una obra; es decir, a través de una actividad del espíritu" (103). Los gestos de esta actividad, asimismo, nos conectan con una subjetividad creadora que, incluso cuando es solitaria, afirma Todorov, se sitúa en un marco de comunicación.

Desde esta perspectiva de la sobrevivencia, la práctica artística teatral -desde la producción y/o la recepción- se comprende más allá del poder de evasión, como ya habíamos anticipado, instalándose, más bien, en un camino creativo un poco más próximo a la belleza en el mundo, "belleza a través de la cual participa uno mismo de lo universal" (Todorov 102) y, a su vez, como un proceso vital de re-concentración de sí -en un marco de comunicación-, que impide y lucha contra la deshumanización.

Por su parte, en el caso chileno, Óscar Castro -actor, director y dramaturgo, quien vivió la experiencia de la prisión política en varios recintos de detención- testimonia acerca de aquello: "El teatro inventa mundos y cuando un hombre se acuerda de que puede crear y reírse, encuentra su libertad dentro de él" (Montealegre, Derecho a fuga 289). En las artes escénicas este proceso implica la colaboración y complicidad de muchos. En una entrevista que realizó Ariel Dorfman a Óscar Castro en la Revista Araucaria de Chile en 1979, le pregunta: “¿Cada obra era una sociedad entera trabajando, eran muchos?", a lo que Castro responde:

cada obra, como cuarenta personas. Además, había gente encargada de las luces, otros responsables del escenario [...]. Tú como creador tenías todas las posibilidades, estando preso, teniendo lo que nunca habías tenido antes. Juntando los cables para las ampolletas de las lámparas de otros compañeros, añadiendo pedazo por pedazo, logramos luz para iluminar el escenario (127).

Este fragmento nos introduce en la dimensión colectiva del teatro. Como expresa Rancière, "el teatro es una forma comunitaria ejemplar. Conlleva una idea de comunidad como presencia en sí, opuesta a la distancia de la representación” (13). La noción de comunidad, parafraseando al autor, se entiende como una manera de ocupar un lugar y un tiempo, como el cuerpo en acto opuesto al simple aparato de las leyes. Aquí, la colectividad se comprende no como una categoría cerrada y homogénea, muy por el contrario, la propuesta apunta a reconocer la singularidad de la aventura intelectual, "que los vuelve semejantes a cualquier otro aun cuando esa aventura no 
se parece a ninguna otra" (23). Rancière refiere al poder que tiene cada uno o cada una de traducir a su manera aquello que él o ella percibe. En ese poder de asociar y de disociar reside la "emancipación del espectador", por tanto, ser espectador requiere desempeñar el rol de intérprete activo. La emancipación significa "el borramiento de la frontera entre aquellos que actúan y aquellos que miran, entre individuos y miembros de un cuerpo colectivo" (25).

Si bien en El espectador emancipado se alude al teatro como un arte asociado a una revolución estética propia de las sociedades democráticas contemporáneas y a la constitución sensible de la colectividad, sus argumentos cobran relevancia para pensar en una comunidad en torno a la narrativa y a la traducción en un estado de excepción como fue la prisión política. ¿La igualdad de la desgracia, que nos señala Montealegre, es vinculante con la escena de la igualdad que nos sugiere Rancière? Por otra parte, ¿la libertad del espíritu que provoca la experiencia teatral tiene características emancipatorias? Son preguntas abiertas para aproximarnos al teatro de Mario Molina.

\section{Campo de Prisioneros Chacabuco: el gesto refundacional}

La experiencia de la prisión política en Chile refiere a la provocada por la dictadura cívico-militar instaurada en septiembre de 1973. La detención masiva fue una de las acciones más significativas de la dictadura, desplegándose desde el extremo norte hasta lo más austral del país. "Para su habilitación se utilizaron todo tipo de inmuebles, desde casas particulares hasta cárceles, regimientos, estadios, piscinas, escuelas, hospitales. Inmuebles que se transforman en lugares para encerrar, para interrogar, para torturar, para hacer desaparecer" (Santos, “Intelectuales en prisión” 20).

Entre estos lugares, la antigua Oficina Salitrera Chacabuco fue un exponente de esta habilitación como centro de detención masiva durante la primera ola represiva de la dictadura, y fue ocupado principalmente por personas presas que fueron trasladadas desde el Estadio Nacional y el Estadio Chile en Santiago. Las más de mil doscientas víctimas de prisión política que pasaron por este recinto militar no respondieron necesariamente a una condena ni fueron una consecuencia de un debido proceso judicial. Fue habitual -explica Jorge Montealegre- que la autoridad representante del Estado no reconociera ni admitiera la existencia de "presos políticos" bajo su régimen; y calificara esta privación de libertad como "detención" y a sus "detenidos" como delincuentes comunes o los connotara con eufemismos, o aplicara categorías amparadas en un estado de excepción, como "prisioneros de guerra". Bajo este marco de denominaciones, "el militante detenido prefiere -aunque calladamente- la denominación de prisionero político o preso político" (Memorias eclipsadas 42). 
Si bien los presos políticos en Chacabuco estuvieron sometidos a condiciones carcelarias autoritarias y rígidas, ${ }^{6}$ pudieron conformar espacios cotidianos a partir de la organización cultural y la creación artística. A diferencia de otros centros y cárceles, Chacabuco arquitectónicamente no era un solo edificio, "sino centenares de casas que conformaban un barrio o una aldea. Por tanto, la vida cotidiana podía desarrollarse fuera de la casa. La vigilancia, salvo los distintos momentos de formaciones y conteos, plantones al sol o allanamientos, en Chacabuco se hacía generalmente desde fuera del campo" (Memorias eclipsadas 35). En efecto, la configuración del espacio y la libertad para desplazarse hacia otras casas o lugares del campo, permitió a los presos conversar entre ellos sin restricciones, vale decir, se pudo dar una dinámica social al interior de Chacabuco.

El contexto geográfico, arquitectónico e histórico de Chacabuco impregna las experiencias que nos dejan los testimonios. En cada relato aparece una imagen, un rincón y un espacio de este lugar. Como expresa Michel De Certeau, "lo memorable es lo que puede soñarse acerca del lugar. Una vez en este lugar palimpsesto, la subjetividad se articula sobre la ausencia que la estructura como existencia y la hace 'estar alli'”' (121). En este sentido, los testimonios de la prisión política en Chacabuco remiten inmediatamente al lugar, no solo por la descripción de los elementos que lo constituyeron como campo de prisioneros políticos, sino también por la novedad que suscitó en los presos el desierto de Atacama y la valoración histórica y simbólica que otorgaron a la antigua oficina salitrera.

¿Qué fue Chacabuco? Primero, fue una pujante oficina salitrera que funcionó entre 1924 y 1938. "En su etapa productiva dio trabajo a cerca de tres mil personas, contando obreros y empleados; sumando el resto de la familia, se calcula en unas diez mil las personas que vivieron en este centro salitrero. Entre ellas, algunos de los prisioneros que llegaron -volvieron- a Chacabuco en 1973"7 (Montealegre, Memorias eclipsadas 28). Posteriormente, en 1972, fue declarado monumento histórico por Salvador Allende. Y solo después del golpe de Estado, en noviembre de 1973, fue habilitado como centro de detención hasta abril de 1975.

6 Podemos afirmar que en Chacabuco sí hubo tortura. Si bien no fueron utilizados los mismos procedimientos de tortura que hubo en el Estadio Nacional o en el Estadio Chile, sí hubo procedimientos vinculados a la tortura. En "La tortura: todo es cuerpo", José Santos expone órdenes de procedimientos implementados por la dictadura sobre los cuerpos, siendo uno de estos la "profanación de los cuerpos", entendiéndose aquellas acciones destinadas a denigrarlos, exponerlos, violentarlos (28). Por su parte, algunos testimonios señalan que las intervenciones de los militares fueron puntuales durante el día, pero en ocasiones allanaban violentamente las casas para requisarles supuestas armas y las herramientas que utilizaban para la confección de artesanías, así como en las noches los sacaban intempestivamente para realizar formaciones militares. Los plantones al sol también fueron otras de las acciones violentas utilizadas por los militares.

7 El caso más emblemático fue el del prisionero político Óscar Vega. A fines de noviembre de 1973 buscó la casa, que se le había asignado como trabajador de la oficina salitrera, para suicidarse. Mario Benavente, en su libro testimonial, escribe: "Sí, había vuelto a su pasado. Allí estaba la misma casa en que formó su hogar. Ahí, el hoyo en que al irse guardó sus herramientas. Ni siquiera el óxido las dañó. No quería que nadie le hablase. Sólo algunos de sus compañeros podían sacarlo de su enconchamiento. No le agradaba que lo hiciesen. Quería, en su hermetismo, revivir tranquilo su pasado. Anhelaba estar junto a su familia. Se sentía arrastrar por un cansancio enorme. Las fuerzas lo abandonaban. Sus raíces lo llamaban. ¿Para qué, entonces, seguir sufriendo esta realidad tan amarga? [...]. Se encontró su cuerpo, pendiendo de una viga, junto a sus antiguos instrumentos de trabajo, cuidadosamente ordenados" (22). 
Pues bien, el gesto refundacional ${ }^{8}$ hace referencia a una nueva fundación de una ciudad o espacio geográfico, la que puede asemejarse a la original, pero al cambiar las circunstancias históricas nace una nueva ciudad. En nuestro caso, una microsociedad masculina de prisioneros políticos. Este proceso se comprende mediante la recuperación y reapropiación de la memoria histórica de la salitrera a través del uso de sus viviendas, calles, utensilios, materiales y desechos, así como el repertorio de palabras adscrito al lugar. Estas estrategias de control de lo nuevo permearon las prácticas artísticas y, a su vez, ciertos espacios como la pulpería; nombre que recibió el lugar que habilitaron los presos para intercambiar alimentos. Fue parte de esta nueva fundación la creación de un consejo de ancianos, ${ }^{9}$ así como de un barrio cívico compuesto por un policlínico, un centro de asistencia jurídica, una biblioteca, una pulpería, un teatro, el diario mural Chacabuco 73, la Universidad Libre de Chacabuco y la demarcación espacial para la realización de diversos deportes (futbol, vóleibol, tenis, etc.). Este variado paisaje organizativo permite identificar un extenso registro de relaciones entre hombres y, por ende, sus conflictos, contradicciones, solidaridades y complicidades.

Los presos en la nueva ciudad comenzaron a bautizar las calles, de acuerdo con sus propios referentes políticos masculinos, como formas de control de lo nuevo y desconocido. Los nombres que las autoridades habían dado en referencia a las victorias de la guerra del Pacífico, próceres de la patria y ciudades chilenas, los presos los modificaron y cambiaron por Allende, Marx, Lenin. Al respecto, Adolfo Cozzi, en su libro testimonial de Chacabuco, relata que "a la calle principal, que desembocaba en el Barrio Cívico, la llamamos en secreto avenida Doctor Salvador Allende Gossens, y para los militares avenida Calama" (50).

Este gesto es posible explicarlo a través de la metáfora del caminante, brindada por de De Certeau, la cual indica el acto de caminar como un acto de habla y un lugar de enunciación con diversas trayectorias e itinerarios. De este modo, el proceso de apropiación del espacio opera a través de prácticas que tejen las condiciones determinantes de la vida social, brindando familiaridad, subvirtiendo y desplazando el orden en la ciudad planificada. Los "nombres propios" son parte de estas prácticas. En los espacios brutalmente iluminados por una razón extraña -sostiene el autor-los nombres propios abren reservas de significaciones ocultas y familiares. "Tienen sentido", dicho de otra forma, "impulsan movimientos, como vocaciones y llamados que cambian y

8 Una perspectiva de análisis que puede nutrir la definición de refundación es la brindada por José Santos en su artículo "La reconfiguración como el modo de llegar a ser. Surgimiento de los centros de detención y/o tortura en el Chile dictatorial", a través del concepto de "reconfiguración", al referirse al proceso de alteración -finalidad, sentido e intervención- de los centros de detención y/o tortura de la dictadura militar chilena.

9 El establecimiento de esta organización representativa de los prisioneros legitima en la esfera pública chacabucana un criterio etario y comunitario de autoridad; y fue probablemente la instancia más idónea para evitar rupturas y divisiones en la comunidad de presos, primando la necesidad de una cohesión interna. Asimismo, el consejo de ancianos fue la organización más importante del campo, porque sirvió de puente comunicacional entre las autoridades militares y los prisioneros políticos. 
modifican el itinerario al darle sentidos (o direcciones) hasta ahí imprevisibles. Estos nombres crean un no lugar en los lugares; los transforman en pasos" (116). En efecto, los presos representan el lugar mediante el uso de los nombres propios, intentando iluminar y dar sentido a lo insensato y aterrador de un campo en el desierto. Así, los presos hacen uso de sus repertorios históricos y políticos aludiendo irónicamente a sus utopías negadas y destruidas y, a su vez, en esta nueva dinámica social reproducen elementos culturales de la izquierda, referentes a la clase obrera pampina y a sus principales teóricos y líderes marxistas.

\section{Escenas y escenarios de Chacabuco}

Chacabuco empezó a resonar en los primeros lugares de detención de la mayoría de los presos políticos. Emerge como un lugar lejano e impreciso geográficamente, así lo expresa Guillermo Orrego cuando les comunicaron que los trasladarían a Chacabuco:

Por el paso que hizo en el Estadio Chile Julio Estuardo, que había sido Intendente de Santiago, supimos que este Chacabuco no era el puerto del sur, porque estábamos medios perdidos, sino que era una ex salitrera abandonada, donde se había hecho la película Caliche Sangriento, que narraba los episodios de la guerra entre Perú y Bolivia y que el presidente Allende lo había declarado monumento nacional, en el año setenta y uno.

Chacabuco fue tomando forma como lugar una vez que llegaron a Antofagasta, luego de un viaje fatídico de tres días desde Valparaíso en las bodegas del antiguo carguero salitrero Andalién. Al respecto, Orlando Valdés (apodado en el campo "el Caliche") rememora la llegada a Antofagasta y el viaje en tren hasta Chacabuco:

La última noche, en el barco, no dejaron dormir a nadie. Todo el mundo de pie.

Nadie duerme. Así que todo el mundo de pie hasta que llegamos a Antofagasta como a las cinco de la mañana [...]. Salió de Antofagasta el tren cuando ya estaba casi amaneciendo, o saliendo casi el sol. Yo me acuerdo que me quedé dormido, como iba sentado. Y cuando abrí los ojos porque el tren se detuvo y empezaron a ordenar a compañeros que se bajaran y subieran a un camión que subía una pequeña cuesta y desaparecía, y no sé para dónde llevaban el camión lleno de presos políticos, lleno de tierra y toda la cosa, porque el terreo que se levantaba era inmenso.

La mayoría de los testimonios estructuran su relato de la llegada a Chacabuco de forma cronológica, tomando como punto de partida, como se ha hecho mención, los primeros lugares de detención. Imbuidos en la percepción de un largo trayecto que los separaba cada vez más de sus familias y sus afectos, enfatizan en las deplorables condiciones a las que fueron sometidos en el Andalién, así como en el pequeño tren 
minero que los trasladó a Chacabuco, cuya marcha obligó a muchos de los prisioneros a enfrentar por primera vez el desierto. Nos relata "el Caliche":

Y ahí desperté cuando voy mirando. Yo nunca había estado en el norte y veo por primera vez el desierto. Nada, nada, nada verde. Todo era de color café, como arena. La estación tenía un arbolito, que sé yo. Pero después mirar hacia el horizonte, nada, nada, ni una casa, nada. El desierto total.

Una vez llegados a la estación de la exoficina salitrera, los subieron a unos camiones directo al lugar de la experiencia. Sumado a la novedad del desierto, aparece la imagen del antiguo pueblo salitrero transformado en campo de prisioneros. Jorge Montealegre lo describe así en su testimonio: "La visión era impresionante porque, bueno, primero porque Chacabuco es muy especial, es un pueblo en medio del desierto. Ya para mí el desierto era una novedad. Y entrar a un lugar donde hay torres de vigilancia, en que hay alambradas, fue bien impactante".

Un aspecto muy significativo en la experiencia chacabucana fue la ocupación de las viviendas de la salitrera, por tanto, también constituye un elemento primario en la descripción de Chacabuco la observación de sus casas y su disposición en el espacio. "El Caliche" nos brinda este recuerdo: "De ahí vimos por primera vez casas. Un cuadrado inmenso, no sé cuántas hectáreas serán y lleno de casas. Pero me llamó la atención de que las casas de los costados siempre daban el respaldo, o sea, las casas estaban hechas hacia el interior del campamento".

En términos interpretativos, esta escena nos ofrece la posibilidad de vincular la historia de la salitrera y la experiencia del campo de prisioneros en torno a la función del diseño urbano de la ciudadela, tanto en la habilitación de espacios de dominación y control como de espacios de resistencia que escapaban a las operaciones programadas y controladas. De algún modo, el espacio ya estaba acondicionado para esta nueva circunstancia histórica impuesta por la dictadura, puesto que "es una ciudadela, originalmente estructurada como un lugar cerrado para que no entraran bandidos ni activistas políticos ni salieran los trabajadores sin ser observados" (Montealegre, Memorias eclipsadas 28).

Un nudo central en el relato de los testimoniantes es el momento de la llegada y el encuentro con las autoridades del campo. Las impresiones sobre lo agreste, lo seco, la ausencia de vegetación y la soledad del norte son interrumpidas con la mención a la bienvenida que recibieron del capitán Carlos Minoletti (apodado por los presos "Chacaletti"):

Pero no había mucho tiempo para mirar el panorama, porque nos hicieron formarnos en ese campo que había ahí en la entrada, nos hicieron poner nuestras cosas, abrir nuestras maletas y tuvimos que sacar todas las pertenencias y ponerlas en el suelo frente a nosotros. Nos hicieron desnudarnos y nos pasaron revista (Sáez). 
Destaca no solo la brusquedad con que fueron tratados y el despojo de las pocas cosas que traían consigo, sino también la orden que recibieron de desnudarse en la cancha de fútbol. Al respecto, el exprisionero político, Hugo Valenzuela, comenta:

Entonces con mucho temor llegamos ahí, porque los quinientos compañeros que nos antecedieron estaban ahí formados esperando que llegáramos nosotros y estaban todos desnudos. Y nos hicieron desnudar también a nosotros. Y fíjate que en un campo de concentración como este pareciera que la desnudez colectiva te provoca un temor terrible porque uno presiente que algo malo va a ocurrir.

A la espera y la incertidumbre se suma la contingencia del lugar, es decir, aquel desierto donde no había "nada" "El Caliche" añade que además de lo espantoso de estar como preso político, de estar obligado, se preguntaba ¿¡cómo voy a sobrevivir aquí!?, y más cuando las posibilidades de fuga eran casi inexistentes en términos materiales, como lo expresa Hugo Valenzuela:

Lo que Allende había transformado en un monumento nacional, Pinochet lo había convertido en un campo de concentración al estilo nazi. Calcado. Con torres de vigilancia. Rejas electrificadas. El campo minado. O sea, era muy difícil poder huir de un campo así. Primero había que sortear todas estas vallas y luego el propio desierto.

Complementa la reciente escena de Chacabuco la descripción que nos brinda Jorge Montealegre:

$\mathrm{Al}$ ser un pueblo abandonado, un sector de él fue cercado y convertido en un lugar vigilado principalmente desde afuera: literalmente un gueto, en su acepción de barrio en que viven personas marginadas por el resto de la sociedad, en este caso confinadas ahí por el Estado. Alambradas electrificadas, minas antipersonales, rondas de tanques, torres de vigilancia y el enorme y árido desierto inhibían cualquier intento de fuga material. Elementos que actuaban por presencia imponiendo la sensación permanente de ser observados. Al otro lado de la alambrada estaba la plaza, el teatro, la iglesia, lo que podría considerarse "el centro" del pueblo (Memorias eclipsadas 29).

La desnudez colectiva constituye la escena que proyecta esta nueva realidad, vale decir, es el momento de la toma de conciencia de estar en un campo de prisioneros donde se concentraban presos que ya habían sido torturados en sus primeros lugares de detención. Se percibe como un lugar de tránsito hacia un destino incierto, enmarcado en un estado colectivo de fragilidad e inestabilidad emocional. En este sentido, como veremos, la planificación diaria de actividades y las prácticas artísticas en general funcionaron como mecanismo psicológico para disminuir el "caldo de cabeza", expresión carcelaria utilizada frecuentemente en Chacabuco, referente a los momentos en los cuales se pensaba y elucubraba "sobre los pro- 
blemas personales y familiares, que de todos modos no tenían solución alguna en esas circunstancias" (Vitale 13).

Podemos afirmar que estas primeras escenas de Chacabuco como campo de concentración son representaciones panópticas que aportan detalles sobre la planificación del espacio y los referentes urbanísticos más significativos. No obstante, De Certeau expresa que "la "ciudad-panorama" es un simulacro teórico (es decir, visual), en suma, un cuadro que tiene como condición de posibilidad un olvido y un desconocimiento de las prácticas" (105). Por el contario, es "abajo" donde termina la visibilidad, donde viven las y los practicantes ordinarios de la ciudad. En un pasado no remoto fueron las y los habitantes de la oficina salitrera, y en su refundación fueron los presos los caminantes de Chacabuco. Bajo esta perspectiva, los practicantes pueden manejar espacios que no se ven y que escapan a la legibilidad y a las lógicas de dominación. “Todo ocurre como si una ceguera caracterizara las prácticas organizadoras de la ciudad habitada" (105), lo cual permite comprender el amplio despliegue de prácticas artísticas, culturales y organizativas por parte de los presos, cuyas trayectorias y desplazamientos movilizan y alteran el espacio. "Una ciudad trashumante, o metafórica, se insinúa así en el texto vivo de la ciudad planificada y legible” (105).

El pasado del lugar se hizo presente a través de la materialidad, impregnando las experiencias que nos dejan los testimonios. Esos tiempos amontonados que estaban allí como relatos y ruinas comenzaron a llenar de contenidos y significados dicha "desnudez colectiva". El propio Jorge Montealegre nos relata en su testimonio cómo se fueron impregnando de la cultura que estaba latente en el lugar:

Curiosamente como que asumimos la historia del lugar, la historia de la pampa. Como que nos hizo sentido a nosotros estar en una oficina salitrera. Por todo lo que significaba dentro de la historia del movimiento obrero. Además, en el imaginario nuestro teníamos la cantata Santa María de Iquique como en la oreja, teníamos esa imagen también.

En efecto, las actuales circunstancias de la detención se llenaron del espíritu de una época pasada. Mario Molina en su cuaderno personal sobre Chacabuco escribió: "rodearon Rodearon las casas de adobe que algún día sirvieron a los obreros del salitre, y son ahora esas nuestras casas. Sobre nosotros el cielo siempre azul, sin nubes, con el sol en pleno pueden caer los rayos como agujas de fuego siempre sobre nuestra piel".

Las descripciones del lugar de la experiencia de la prisión política, a través de estas escenas compuestas por los testimoniantes, colaboran en el diseño de Chacabuco como un gran escenario de la violencia política y represión estatal, pues aquí se perfilaban las condiciones apropiadas (geográficas, arquitectónicas e históricas) para vigilar, controlar y dominar los cuerpos detenidos y, con ello, desarticular al sujeto político. Es decir, un escenario "brutalmente iluminado por una razón extraña" (De Certeau 116). No obstante, de acuerdo con la propuesta argumental sostenida en este artículo, el proceso de apropiación y refundación del espacio por parte de la 
comunidad de presos operó a través de prácticas que tejieron las condiciones determinantes de la vida social, brindando familiaridad y, a su vez, subvirtiendo el orden en la ciudad planificada.

Bajo este enfoque, la práctica artística teatral subvierte la ciudad-panorama permitiendo la emergencia de otros escenarios y nuevas escenas chacabucanas. Al respecto, Mario Molina nos comparte el siguiente fragmento de sus notas personales:

Esto está escrito el mismo día que llegamos allá: Hemos creído necesario establecer una academia teatral, guardando las debidas proporciones, en la cual pueden verter sus experiencias, nuestros más expertos en dirección teatral, expresión corporal, voz, historia del teatro, análisis del teatro actual, etcétera.

Los aficionados al arte dramático resolvieron organizarlo de acuerdo a una diversidad de estilos -teatro clásico, teatro experimental y pantomima-:

El grupo de teatro quedó organizado en los primeros días de nuestra llegada al campo de Chacabuco. Después de asistir a varias reuniones, los primeros componentes acordaron reunir a los interesados en tres grupos, A, B y C. Aquí tienen, por ejemplo, representante del grupo A, Juan Fuentes, Grupo B, representante Mario Molina, Grupo C, representante Abdón Barrientos [...]. La idea fundamental de los tres grupos ha sido permitir en primer lugar, juntar a la gente de teatro con ideas afines, establecer un equilibrio entre personas con experiencia teatral y otras sin ninguna, al mismo tiempo que permitir el trabajo creador que tiende a establecer escuelas o tendencias, por ejemplo: una escuela de teatro realista, otra de teatro de improvisación, etc., etc. (Montealegre, Derecho a fuga 279).

La razón que aduce Mario Molina a la organización del teatro en Chacabuco refiere a la tendencia natural de reunirse entre personas afines en inquietudes, profesiones $\mathrm{u}$ oficios. Como dice Montealegre: "los teatristas se reconocen y empiezan a reunirse" (Derecho a fuga 280). Pero también, a modo de complemento, podemos añadir que la organización del gremio teatral se debió a una forma de proyectar una continuidad biográfica. Sabemos que la prisión política fue una experiencia de quiebres biográficos y trayectorias interrumpidas, $y$, como en cualquier otro sitio, los hombres encerrados debieron enfrentar una realidad determinada y modificarla por medio de estrategias individuales y colectivas de sobrevivencia.

\section{La actividad cautiva: el teatro de Mario Molina}

El teatro de nuestro autor se inscribe en una experiencia comunitaria que escenifica los imaginarios y deseos colectivos en los nuevos escenarios de Chacabuco. Desde este prisma, la reconstrucción testimonial de escenas y escenarios -desde distintas voces y horizontes temporales- habilita la emergencia autoral para la creación teatral. 
La aparición de Mario Molina en la esfera pública chacabucana tiene ciertamente una impronta colectiva por las características propias de las artes escénicas, pero también su presencia encuentra solitariamente un lugar para la realización de su ejercicio escritural. Montealegre reconstruye esta escena: "Mario Molina y otros compañeros, entonces, ocupan una casa abandonada y -relata con orgullo- 'levantamos con nuestras propias manos un pequeño teatro'. Solitario, Molina se fue a vivir a 'su' casa-teatro, lo que le valió el apodo 'el fantasma de la ópera'” (Derecho a fuga 281). El acto de autor de Molina, en su doble régimen de transmitir e inquietar la incomunicabilidad de los acontecimientos, encuentra un lugar literalmente en la ocupación de una casa abandonada:

La vez que empecé a escribir en serio fue ahí, la vez que nos organizamos, cuando me quedé yo en esa casita que tú viste, encerrado y que estaba bien taponeada para que no se vieran luces, porque Chacabuco estaba guardada por guardias, y los guardias nunca se enteraron que ahí había un individuo que ahí estaba con la luz prendida y algo malo estaba haciendo, porque no podían ser cosas buenas, lo decía el dictador. Estaba todo el día ahí, y nadie se enteraba que yo estaba todo el día ahí, salvo Jorge Montealegre que nos juntábamos a tomar tecito. Y así pasaba el tiempo.

De este modo, se construye un teatro y se nombra, vale decir, se otorga un nombre propio, cambiando el itinerario de los sentidos o direcciones hasta ahí imprevisibles. Como dice De Certeau, "estos nombres crean un no lugar en los lugares; los transforman en pasos", en otras palabras, estas apariencias de lo propio se sostienen por "un universo de sitios obsesionados por un no lugar o por los lugares soñados" (116). Mario Molina representa esta otra espacialidad como una experiencia poética y lo relata de esta forma en su testimonio:

Este teatro al que le llamamos teatro no era un teatro, era una casa que se estaba cayendo. Más allá estaba la calle, una calle ancha que medía kilómetros, que es Chacabuco. Esta calle se llama Lynch. Y Toscano Sáez hizo este dibujo tal cual. Nosotros para ir a ver cualquier cosa que queríamos teníamos que meternos por aquí, por una puerta de calle y teníamos que atravesar por donde habíamos puesto de escenario. Aquí hay una inspiración, "mijita", sobre lo que nos gustaría que hubiera sido un teatro, pero resulta que así no estaba. Estaba el auditorio de presentaciones y yo estaba pensando para Santiago.

Para ir a ver esto, teníamos que entrar desde la calle. Acá está el patio con los asientos de madera y están las paredes que hubo que ponerles un palo para que no se cayeran las paredes [sic]. Lo único que está abierto era esto, el único lugar donde se puede entrar. Entonces atravesar el pasadizo, lo que aquí queríamos que fuera la sala de actuaciones y los asientos de madera para que se sentaran más o menos cien personas. ¿Qué es lo que había sucedido? Es que cuando se atrasaban, el público, tenía que pasar a través de la obra de teatro, ya estábamos 
FIGURA 1

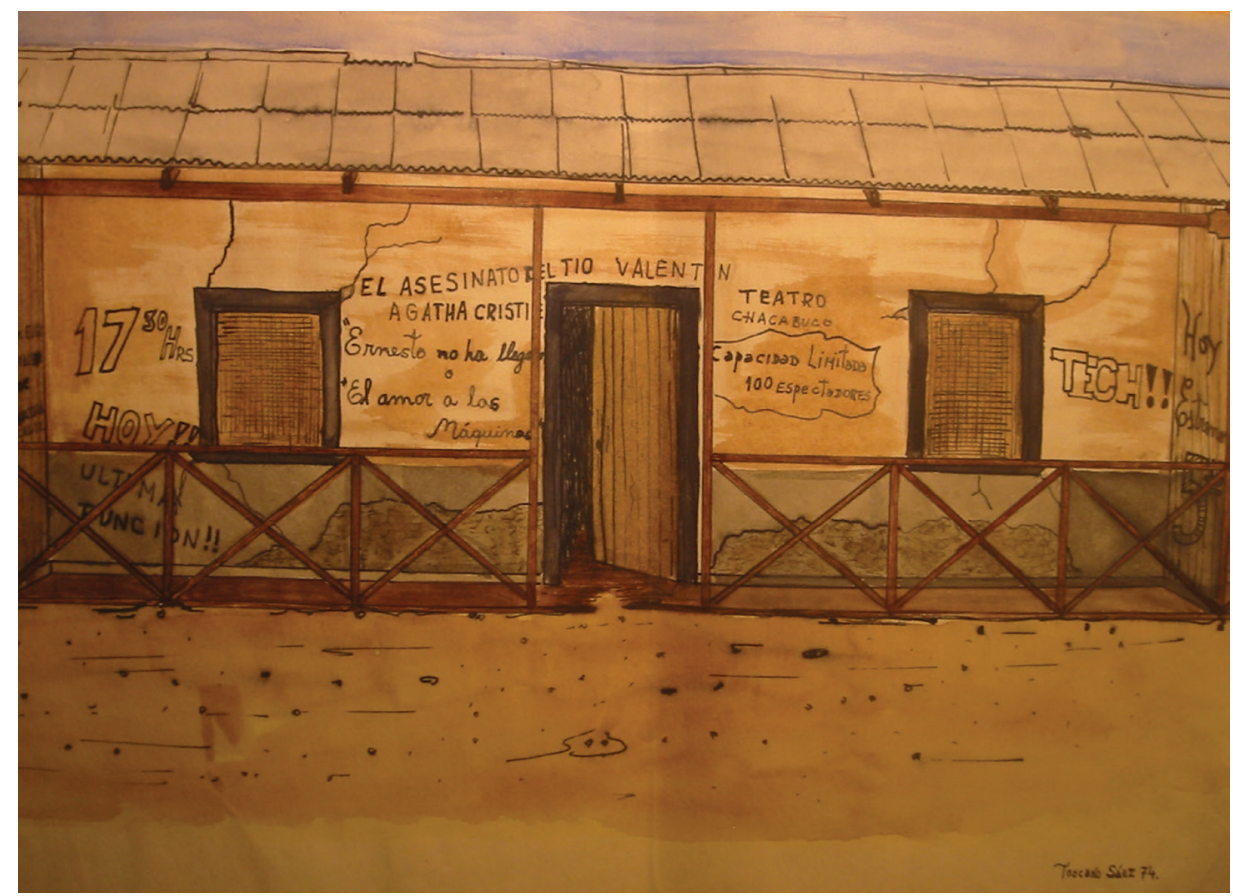

Dibujo de Juan Carlos Sáez realizado en el Campo de Prisioneros de Chacabuco.

Fuente: Archivo personal de Mario Molina.

trabajando, con los locos, entonces pasaban otros locos atravesando el pasadizo, para atravesar un patio de actuaciones, al otro lado estaba el patio de la casa para poder ver lo que pasada [sic] acá. No era un teatro bonito con todas las de la ley ni nada.

El dibujo de Juan “Toscano" Sáez al que alude Mario Molina fue titulado Teatro Chacabuco y representa el reconocimiento en la esfera pública chacabucana de la existencia del teatro de Mario Molina. Juan Sáez, como testigo directo, relata que cuando se enteró de la existencia de su teatro asistió a ver un par de obras. Este encuentro y las conversaciones que mantuvieron entre ambos durante la prisión motivó a Juan Sáez a participar en la actividad teatral. Así lo recuerda:

En un par de ocasiones le estuve ayudando a organizar las mesas en el patio de atrás donde se hacían las presentaciones, las obras. Le estuve ayudando con un poco de carpintería, mi hobby siempre ha sido la carpintería, entonces le ayudé a arreglar sillas y bancas, porque eran bancas de tablas nomás [...]. A raíz de eso se me ocurrió por suerte hacer un dibujo del frontis de su teatro que él llamo teatro experimental de Chacabuco. Hice un dibujo del frontis porque era muy divertido como estaban anunciadas las obras. Había una que 
decía El asesinato del tío Valentín o El amor a las máquinas. Estaba el horario de la función. 100 espectadores máximo. Y todo eso lo capté de forma bastante realista. Que por suerte se me ocurrió hacerlo que [sic] ahora sirve de muestra de una parte de nuestra historia.

Sus palabras muestran una expresa disposición a colaborar en la escena teatral en relación con lo que Montealegre esgrime: "todos podían tener un papel en esta forma de adaptación teatral, de juego social, que imponía la emergencia. El que no actuaba, ponía su trabajo o ideas para la producción o participaba en la búsqueda de recursos para que las ideas se llevaran al escenario" (Derecho a fuga 281). Asimismo, tanto el dibujo como los testimonios de Mario Molina y Juan Sáez refieren a una dimensión material del espacio, pues ambos perfilan su definición de acuerdo con una función específica y los recursos disponibles para su uso. De otra forma, podemos decir que se realiza una teatralización de los espacios.

En términos de la reconstrucción de las escenas y los escenarios en Chacabuco, el dibujo del frontis del teatro nos provee de información valiosa ligada a lo que en otras circunstancias sería una cartelera teatral: nombre del teatro (la sigla TECH, de Teatro Experimental de Chacabuco, probablemente fue en alusión a la sigla TEUCH del Teatro Experimental de la Universidad de Chile), nombre de las obras, horario de las funciones, estrenos, así como la cantidad de público que podía acoger. El gesto testimonial de Juan Sáez está inscrito en su propia práctica artística -el dibujo-, que hoy precisamente testimonia los vestigios del teatro de Mario Molina. ${ }^{10}$

El reconocimiento público del teatro también se encuentra en la voz de Hugo Valenzuela, quien afirma que Mario Molina se transformó en el eje y motor del teatro. En su relato también refiere a la presencia de compañeros que eran profesionales de la actuación, como

el compañero de apellido Palta, que era un actorazo. Y los compañeros que empezaron a participar del teatro empezaron a ensayar diariamente con una disciplina impresionante porque empezaron a hacer teatro de verdad. Y Molina estaba tan dedicado a esto que se metió a vivir a la casa, día y noche, escribía libretos, escribía adaptaciones de las novelas de Agatha Christie. Y como vivía en el teatro le pusimos el fantasma de la ópera y hasta el día de hoy todo el mundo le dice el fantasma de la ópera.

Este fragmento ilumina acerca de la disciplina de los actores, la que requería una dedicación ardua y cotidiana. Sabemos por Montealegre que Gonzalo Palta fue un actor profesional, no obstante, muchos de los participantes nunca habían actuado e incluso algunos tampoco habían asistido al teatro. Este cuadro descriptivo se complementa

10 La colección de dibujos de la prisión política de Juan Carlos Sáez Calderón (1973-1974) se encuentra disponible en la sección Archivo de Fondos y Colecciones del Museo de la Memoria y los Derechos Humanos. 
con el relato de Óscar Castro acerca de su experiencia en los campos de prisioneros Tres Álamos y Ritoque:

Yo trabajaba con los compañeros todos los días, y durante todo el día. A los tres meses ya eran actores profesionales, y hacíamos espectáculos de tanta o mejor calidad de lo que estábamos haciendo afuera. Se entregaban enteros. Se aprendían las obras en una semana, sacaban personajes, estudiaban (Dorfman 134).

El teatro de Mario Molina no tiene un origen profesional en términos de estudios universitarios o de amplia trayectoria artística previa a la prisión política; él adquirió su conocimiento teatral cuando era ingeniero en la Empresa Nacional de Electricidad (ENDESA) como un espectador asiduo a las obras de teatro de la Universidad de Chile, de la Universidad Católica de Valparaíso y de la Universidad de Concepción. Asimismo, podemos agregar que su escritura teatral emerge desde la necesidad de hacer cultura como un gesto político de continuidad del proyecto de la Unidad Popular en circunstancias extraordinarias. El siguiente trozo testimonial proyecta la posibilidad de acción del arte y la cultura que encuentra nuestro dramaturgo para comenzar en Chacabuco a escribir "en serio" (como él mismo declara) para enfrentar la derrota de la utopía: "El teatro viene por interés de estas cosas de cómo este país se está construyendo culturalmente. La cultura no se fríe como una presa de pescado, hay otras motivaciones. Llega la cultura y tú la guardas para que te sirva, para este país largo y flaco, para este país que quieren destruir".

Pues bien, de acuerdo con los testimonios de Juan Sáez y Hugo Valenzuela, observamos que se mencionan los nombres de dos dramaturgias. La primera, titulada El amor a las máquinas, no aparece publicada en el corpus dramático de Molina de 2008, en cambio la obra El asesinato del tío Valentín, adaptación de la novela de Agatha Christie El Misterio de Hunter's Lodge, fue presentada en varias ocasiones. En cuanto a las adaptaciones, Mario Molina en su testimonio refiere a las complejidades que revestía hacerlas, debido, en parte, a la ausencia de mujeres y, a su vez, porque "no estaban las condiciones escenográficas donde se movía la obra, no había muebles, ni las calles, ni la iluminación, entonces había que adaptarse a esas condiciones". De este modo, se infiere que, por la dificultad reportada y por la extensión de la escritura que podía implicar una adaptación, Mario Molina fue combinando la composición de sus obras dramáticas con un formato más breve, los gags - "esos pedacitos de obras que yo escribí"-, los que garantizaban un menor tiempo de preparación escritural y producción escénica en personajes, escenografía y ensayos. Además de lo dicho, se sumaba la dificultad de reproducción de los libretos, sobre lo que el dramaturgo expresa irónicamente en su relato: "No había máquina de escribir en realidad, se habían arrendado o las habían vendido, había que escribirlo con un papel calco para sacar dos copias nomás".

En los gags comenzaron a aparecer temas más humorísticos, "unas que se pueden dar ahí y otras que no se pueden, que se escriben nomás” -señala el autor-. El uso de 
la ironía y el absurdo dieron forma a varios de sus gags. Entre estos, destaca el primero de la publicación de 2008 ¿Quién está cuerdo?, farsa en un acto derivada del gag Locos, escrita y presentada en Chacabuco en 1974. Aquí Mario Molina traza elocuentemente los niveles de lo que él dice "se pueden dar ahí y otras que no se pueden" dar en un campo de prisioneros. El escenario perfecto es una casa de orates para el diálogo entre un periodista, tres médicos y un psicólogo. Quien inaugura la trama es el periodista, presentándose como periodista del diario El Mercurio. "Se dirige al público. Tengo que hacer un artículo respecto de los orates de este país... Hay tantos y sueltos por todas partes" (Molina 22). "El médico 1", luego de responder a las preguntas, desaparece de escena en busca de Cotocó (la señora que pone huevos), un caso preocupante del manicomio. En instante irrumpe "el médico 2", quien desmonta la credibilidad del diálogo al evidenciar la locura del supuesto médico: "Usted conversó con nuestro alienado que se cree médico, que se apropia de ropa de los verdaderos médicos que tenemos acá" (25). En efecto, la fachada de la cordura se va desplomando sucesiva y rápidamente ante la aparición de otro loco que se va disputando la cordura. Finalmente, es el secretario de la casa de orates quien se encarga de iluminar la farsa de los personajes, incluido el periodista que grita: "Suéltenme, suéltenme, estoy cuerdo. ¡Cuerdo! Soy del Mercurio. ¡Auxilio!... ¡mamaaá! (27). Esta escena releva la pregunta que lleva por título el gag ¿Quién está cuerdo?, puesto que, previo a que se corra el telón, el secretario se dirige al público diciendo: "Son todos simuladores a los que hay que seguir la corriente... Y ustedes señores también lo son (marca con el dedo al público). Sí, simuladores y locos" (27).

Observamos que el contenido de los diálogos, así como sus figuras enunciantes, están cargados de referencialidad al brindar imágenes de la crisis social y, en particular. por la difusa frontera que se traza entre la cordura y la locura en un campo de prisioneros políticos. Como se ha señalado anteriormente, a partir de los testimonios, Chacabuco se percibe como un lugar de tránsito hacia un destino incierto, enmarcado en un estado colectivo de fragilidad e inestabilidad emocional. La salud mental fue una preocupación central en la comunidad de presos, donde los médicos tuvieron un rol fundamental. En este sentido, la planificación diaria de actividades y las prácticas artísticas en general funcionaron como un mecanismo psicológico para disminuir "el caldo de cabeza". Veamos un extracto:

Periodista: Dicen que los orates tienen mayor sensibilidad que las personas consideradas normales... ¿Existen o detectan ustedes manifestaciones artísticas notables entre ellos?

Médico 1: Sí... sí (preocupado) los más enajenados se han dedicado al teatro y existen buenos actores y buenas actrices... otros menos locos pintan. Han organizado también, con nuestra ayuda, un taller de grabado en madera... Hasta un coro tienen. Algunas veces montan y presentan verdaderos shows artísticos los fines de semana para sus familiares que los visitan (23). 
La necesidad de nuestro "Escribidor" de representar bajo estos códigos la experiencia en Chacabuco ciertamente está atravesada por su sensibilidad de creador, pero, asimismo, por su propia comprensión de las circunstancias históricas, deviniendo en un teatro de autor. No obstante, se requería que otros prisioneros, además de él, participaran de dicha experiencia reflexiva. De alguna manera, el teatro de Mario Molina refuerza la igualdad de la desgracia en la comunidad chacabucana, pero también la capacidad de subvertir la norma, muchas veces desde la complicidad con el contenido del humor, pues todos sabían que se estaban riendo de lo mismo. En este sentido, el humor, el sarcasmo y la ironía operaban como posibles actos de fuga para destejer los hilos de la represión. Lo más probable es que la impronta de su dramaturgia se pueda explicar a través del siguiente fragmento de su cuaderno personal:

Nunca he sentido el absurdo con más claridad y plenitud que en el campo de prisioneros de Chacabuco. Toda la situación vivida a nuestro arribo nos contradecía la razón y la emoción. La sorpresa y la estupefacción en un fondo de vacío y angustia fue nuestra vivencia de los primeros momentos.

Esta reflexión inaugural de su experiencia en Chacabuco nos transporta al nudo dramático de su ejercicio artístico. El descubrimiento del absurdo fue el motor para explorar teatralmente y escenificar la locura, la irracionalidad, la angustia y la incomunicación. Ahora bien, en un horizonte temporal muy distante a la escritura de este texto, en el marco de la entrevista de mayo de 2015, se le pregunta: ¿En Chacabuco qué temas lo inspiraban? En su respuesta dice: "hay muchos temas, la angustia, el sentir, de dónde se saca esta cosa que se podría decir energía, de odiar y de querer de una persona, de dónde lo saca, por qué lo saca. Eso es más o menos lo que me inspiraba”. Asimismo, en esa entrevista enfatiza la "mala dirección del Fantasma de la Ópera", aduciendo que él "estaba más preocupado de la salud mental de los compañeros, para que se portaran bien, incluso que se pusieran zapatos para que no se resfriaran....

En relación con el tema de la incomunicación, Mario Molina dedicó un gag y un trozo dramático. El primero se llamó La incomunicación, y el segundo, Primero incomunicación, luego..., ambos de 1974. En el trozo dramático se construye una escena que transcurre en el patio de una casa semidestruida. Los primeros diálogos remiten a una discusión acalorada entre dos actores, donde uno de ellos muestra su enojo por el retraso de sus compañeros para el ensayo. Esta discusión es interrumpida por la llegada del director, quien dice: "Mira Ricardo. No están aquí debido a que cuando venían en grupo a trabajar al teatro los interceptó una patrulla y los llevó... voluntariamente, al otro lado de la reja electrificada a retirar escombros. (Se calman los ánimos. Trabajan, ahora en silencio, con más entusiasmo)” (42). No obstante, el director propone a los dos actores presentes un nuevo libreto para ensayar. Una vez que el escenógrafo acondiciona el espacio para el ensayo, observamos que se interrumpe por un apagón de luz. Por tanto, con la luz de una vela y una taza de café ocurre un giro en la escena: el director comenta que recién ha terminado de leer el poema 
de Ricardo (de apellido Cartagena), Despierta Chacabuco, y junto al otro actor y el escenógrafo le piden que recite la poesía. El escenógrafo acompaña la declamación con los acordes de una guitarra.

El actor-poeta Ricardo Cartagena refiere a la llegada de los presos a Chacabuco, a "obreros del arte, la ciencia y el pensamiento, de la máquina, el calco, el oficio [...]" (44). Pese a sus diferencias "vienen todos por el mismo camino" (44). Vemos que el gesto refundacional reaparece en esta poesía, así como el reencuentro con la historia pasada y olvidada de la antigua salitrera: "prisioneros habitan las casas y remueven el polvo del olvido. Se confunden los olores [...]" (44). Despierta Chacabuco también es un recuerdo profundo y doloroso de los que quedaron al margen de ese camino: "atrás quedaron los niños creciendo huérfanos de padre vivo [...]" (44). Y la mujer [...] de vientre fecundo, vacío su cuerpo, marchito en soledad" (44). Remachando con esta última estrofa:

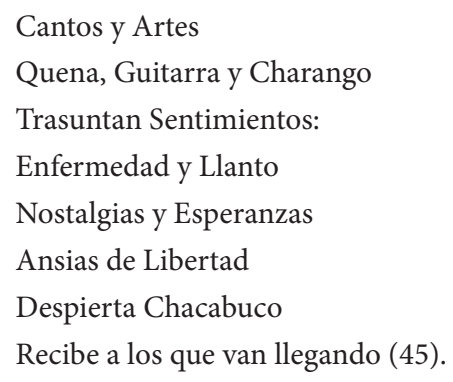

El otro actor, Guillermo Cisternas, también se presenta como poeta y su poema se titula Así pasen mil años. La fuerza de sus palabras radica en la pregunta por la existencia en Chacabuco, “¿Estoy en los confines del tiempo, sin memoria, nombre, ni distancias?” (45). En este tiempo suspendido donde el poeta se re-conoce en su dimensión solitaria aparecen los pasos y la voz de una mujer, y declama:

Decidme si es la de siempre su sonrisa,

Si tienen color de olvido sus ojos

Y su boca se mueve como besando el aire.

Adiós, no queda tiempo,

Zarpa la noche,

La ausencia es larga, tendrás

Que esperarme hasta que vuelva,

Así pasen mil años, amor

En la misma esquina (47).

Pues bien, después de estas enunciaciones poéticas la escena se reestablece reflexionando sobre lo que acababa de suceder en la voz del director: "Es curioso como los poemas que han recitado, así como nos retrotraen a este lugar y nos recuerdan que 
estamos encarcelados, también nos transportan hacia nuestros seres queridos" (47). La poesía emerge como una expresión dramática del lugar del encierro y, a la vez, como una posibilidad de conexión con los afectos y con aquellos que permanecen en el recuerdo. Esta imagen se materializa en las palabras del Actor 1, quien dice: "Realidad e ilusión al mismo tiempo" (47). El giro que clausura la escena es cuando el director manifiesta: “¿No les parece que esta reunión en la cual participamos es teatral? Y si es así ¿Por qué no repetirla ante los demás prisioneros de Chacabuco?” (48).

La descripción de este trozo dramático expone una multiplicidad de cuadros relativos a la práctica teatral, la que habilita la escena para que ocurra el acontecimiento central, que es el acto poético. En efecto, "el teatro se transforma, de este modo, en una experiencia directa de lo real, instalándose como un acontecimiento y bajo la auto-presentación del artista, cuya vinculación con la realidad política y corporal que lo rodea queda abiertamente expuesta" (Grumann 129).

Al mismo tiempo, podemos decir que es una obra que realiza una reflexión sobre el teatro y sus posibilidades representacionales. La propuesta final del director expresa el deseo de repetición del acontecimiento y donde incluso se señala, en la voz del escenógrafo, que se presente con "apagón, velas y café", a lo que agrega el director: "paso a paso, tal como se fue realizando esta noche ante un público inexistente" (48).

La hipertextualidad de la puesta en escena invita a pensar acerca de los juegos entre la realidad y ficción y, a su vez, en cómo opera performáticamente, suspendiendo y transformando el tiempo y el espacio. De esta manera, Mario Molina, en su gesto de borradura del límite ente la realidad e ilusión, el teatro y no teatro, y el principio y el fin, nos conduce a su propia experiencia estética.

Un año antes de su muerte, Mario Molina, en su reflexión acerca de su dramaturgia, es consciente de que, en su ejercicio creativo, de alguna forma, también estaba refiriendo a una experiencia nacional de prisión política más allá de las particularidades de Chacabuco:

El teatro que yo escribo acá, lo que puedo hacer de obra, incluyo otras cosas e incluyo también a otros compañeros que nunca pasaron por Chacabuco, pero pasaron por Isla Dawson, Estadio Nacional, todos los campos, porque Chile en ese periodo era un largo campo de concentración. Porque no olvidemos que en Chile estábamos sujetos a esto que se llamó dictadura.

\section{A modo de conclusión}

El propósito de este artículo fue abordar lo testimonial desde la práctica artística teatral a partir de la dramaturgia escrita por Mario Molina durante su experiencia de prisión política en Chacabuco, en la dictadura militar en Chile. Lo testimonial se inscribe, por una parte, en el reconocimiento de la obra dramática -y del arte en general- como forma de conocimiento y, por otra, en el acto de autoría. En el caso 
de Mario Molina, su gesto de creador se enlaza con su dimensión de testimoniante en su publicación Teatro en Chacabuco en 2008.

Afirmamos en este artículo que las prácticas artísticas son productoras de otras realidades que transforman y suspenden transitoriamente la realidad impuesta, es decir, son actos performáticos. La utilización de esta definición cobra sentido para comprender que las prácticas son registros que quedaron de una normalidad construida en una excepcionalidad, como forma de interpretar los nuevos hechos que sucedieron en la prisión política. Desde este lugar, la práctica artística se estableció como un modo de operación, un quehacer (individual y colectivo) y un proceso comunicativo en circunstancias límites.

El motivo de esta reflexión fue pensar las obras de Mario Molina y su puesta en escena desde una perspectiva más allá de su carácter evasivo, pues bajo el marco de lo testimonial estas fueron analizadas desde la relación del arte con lo real y, a su vez, como obras abiertas a variaciones de sentido e interpretación. El carácter testimonial tiene un horizonte temporal distinto al momento de la producción y de la emergencia de la práctica artística en la prisión política.

En este artículo otra perspectiva de análisis abordada fue la categoría de actividad del espíritu de Todorov, para situar a las prácticas artísticas en un campo de posibilidad de belleza y de un proyecto creador en la prisión política. Desde aquí pudimos proponer la idea de un proceso vital de "re-concentración" de sí mismo, cuyo efecto fue la suspensión y transformación transitoria de la realidad impuesta, impidiendo con ello la deshumanización. En el ámbito teatral la experiencia es colectiva pues, como observamos, el ejercicio teatral en la prisión política implicó la colaboración y complicidad de muchos participantes. En este marco, podemos agregar al proceso de "re-concentración" de sí mismo el traspaso de responsabilidad del autor-intérprete al público como un redescubrimiento verdadero de este último.

La mención al gesto refundacional se justifica en relación con la resignificación que los propios presos hicieron del lugar mediante sus experiencias, así como en vehicular la construcción de una cierta normalidad en el ámbito cotidiano. La metáfora del caminante de Michel de Certeau -acto de caminar como un acto de habla o un lugar de enunciación- actúa de guía para trazar las diversas trayectorias que desplazaron y modificaron la ciudad planificada.

En este sentido, se fueron configurando escenas y escenarios en la antigua salitrera. La escena de la desnudez colectiva fue la que proyectó esta nueva realidad, es decir, Chacabuco como un lugar de tránsito hacia un destino incierto y enmarcado en un estado colectivo de fragilidad e inestabilidad emocional. En otras palabras, Chacabuco aparece como un gran escenario de la violencia política y represión estatal, brutalmente iluminado por una razón extraña, como señala De Certeau. En contraposición, como hilo argumental utilizado, la práctica artística teatral subvierte la "ciudad-panorama" permitiendo la emergencia de otros escenarios y nuevas escenas chacabucanas. 
El acto de autor de Mario Molina, en su doble régimen de transmitir e inquietar la incomunicabilidad de los acontecimientos, encuentra lugar literalmente en la ocupación de una casa abandonada. En efecto, nuestro dramaturgo representa esta otra espacialidad -su teatro- como una experiencia poética. Desde la identificación de un nuevo escenario fue posible reconstruir las dramaturgias del autor a través de distintas voces testimoniales y horizontes temporales, los que nos aproximaron a sus textos como a la escenificación de los mismos, reafirmando la existencia de gestos emancipatorios a través de la representación teatral y las relaciones entre el artista y la comunidad espectatorial.

\section{Agradecimientos}

Mis especiales agradecimientos al autor de estas obras, Mario Molina Domínguez, quien fue muy generoso en recibirme en su casa y compartir su memoria y notas personales de la prisión. Con mucho afecto también agradezco a su esposa, Gilda Echeverría, y a su hijo Marko Molina, quienes fueron cables a tierra cuando Mario divagaba en las profundidades de los átomos y el tiempo.

\section{Referencias}

Benavente, Mario. Contar para saber. Chacabuco-Puchuncaví-Tres Álamos 1973-1975. Santiago, Talleres de J\&C Productores Gráficos, 2003.

Comisión Nacional sobre Prisión Política y Tortura. Informe de la Comisión Nacional sobre Prisión Política y Tortura, Ministerio del Interior, 2005.

Cozzi, Adolfo. Chacabuco. Pabellón 18, casa 89. Santiago, Sudamericana, 2001.

Derrida, Jacques. "Poética y política del testimonio". Revista de Filosofía, Universidad Iberoamericana, ${ }^{\circ} 113,2005$, pp. 11-47.

Diéguez, Ileana. "La práctica artística en contextos de dramas sociales". Latin American Theatre Review, Fall, 2011.

De Certeau, Michel. "Andares de la ciudad". En La invención de lo cotidiano. 1. Artes de hacer. México, Universidad Iberoamericana, Instituto Tecnológico y de Estudios Superiores de Occidente, 1996, pp. 103-126.

Dorfman, Ariel. “Óscar Castro: El teatro en los campos de concentración". Araucaria de Chile, no 6, segundo trimestre, 1979, pp. 115-147.

Grumann, Andrés. "Performance: ¿disciplina o concepto umbral? La puesta en escena de una categoría para los estudios teatrales". Apuntes de Teatro, no 130, 2008, pp. 126-139.

Hall, Stuart. Representation. Cultural Representations and Signifying Practices. Londres, Sage Publications, 1997. 
Jay, Martin. La crisis de la experiencia en la era postsubjetiva. Santiago, Universidad Diego Portales, 2003.

Mauro, Sebastián. "La obra de arte como forma de conocimiento. La forma paradójica de la mimesis en Aristóteles y Adorno". A Parte Rei. Revista de Filosofía, n 41, septiembre, 2005, pp. 1-9.

Molina, Mario. Teatro en Chacabuco (Campo de concentración). Santiago, ChileAmérica- Cesoc, 2008.

Montealegre, Jorge. Memorias Eclipsadas. Duelos y resiliencia comunitaria en la prisión política, Santiago, Asterion, 2013.

- - Derecho a fuga. Una extraña felicidad compartida. Santiago, Asterión, 2018.

Portelli, Alessandro. "El uso de la entrevista en la historia oral". En Historia, memoria y pasado reciente, vol. 20, Anuario Escuela de Historia. Universidad Nacional de Rosario, Homo Sapiens Ediciones, 2005.

Rancière, Jacques. El espectador emancipado. Buenos Aires, Manantial, 2011.

Santos, José. "La tortura: todo es cuerpo". Revista de la Academia, vol. 20, Santiago, 2015, pp. 27-45.

- - . "La reconfiguración como el modo de llegar a ser. Surgimiento de los centros de detención y/o tortura en el Chile dictatorial". Aisthesis, n 60, Santiago, 2016, pp. 145-165.

- - "Intelectuales en prisión. Resistencia cultural en los espacios del terror de la dictadura chilena”. Palimpsesto, vol. viII, no 11, Santiago, 2017, pp. 19-36.

Taylor, Diana. Performance. Buenos Aires, Asunto impreso, 2012.

Todorov, Tzvetan. Frente al límite. México, Siglo xxi, 2004.

Vitale, Luis. La vida cotidiana en los campos de concentración de Chile. Caracas, Universidad Central de Venezuela, 1979.

\section{Fuentes testimoniales}

Entrevista a Mario Molina, 16 de mayo de 2015, Santiago de Chile.

Entrevista a Guillermo Orrego, 13 de junio de 2015, Santiago de Chile.

Entrevista a Jorge Montealegre, 18 de julio de 2015, Santiago de Chile.

Entrevista a Hugo Valenzuela, 20 de diciembre de 2015, Santiago de Chile.

Entrevista a Juan Sáez, 9 de febrero de 2016, Santiago de Chile.

Enviado: 8 octubre 2018

Aceptado: 26 mayo 2021 